\title{
Esmagando a Hydra da discórdia: o enquadramento do pensamento exaltado pela moderação mineira
}

Wlamir Silva*

\section{Resumo:}

Na construção da identidade moderada mineira, fundamental para a confecção de sua hegemonia, foi inestimável a sua delimitação pelos elementos que lhes eram potencialmente perigosos ou que se lhes opunham. Dentre estes destacamos aqui o liberalismo exaltado. O liberalismo exaltado mineiro foi, essencialmente, uma ausência. Para isso, porém, concorreu a pedagogia liberal-moderada, caracterizando-o como violento e irracional, apaixonado, vingativo e ambicioso, em oposição à razão moderada, e veículo de uma revolução sangrenta, envolvendo gente de cor e incautos e ignorantes. Desta forma, interpretando e influenciando a sociedade de abastecimento mineira, os liberais moderados lograram isolar o "vírus exaltado", impondo a sua lógica e exercendo a sua hegemonia.

Palavras-chave: Cultura política, identidades políticas, hegemonia política.

A historiografia sobre o período regencial brasileiro (1831-1840) persiste na trifurcação clássica das tendências políticas do período: moderados, exaltados e restauradores ${ }^{1}$. A conformação desse quadro partidário, ou protopartidário ${ }^{2}$, em que pesem suas limitações, é a referência de análise para o período. De fato, a definição clara da cisão dos liberais foi, sobretudo, uma característica da dinâmica política da Corte do Rio de Janeiro ${ }^{3}$.

Os estudos sobre a Província de Minas revelam uma dicotomia entre liberais moderados e restauradores (Iglesias in Holanda, 1985, p.364-412, 399). Não existiram exaltados em Minas, ao menos de forma minimamente organizada. Não existiram periódicos exaltados ou ações políticas significativas típicas daquela facção, se tomarmos como modelo o Rio de Janeiro. Em Minas, o Partido Moderado afirmou uma clara identidade em contraposição aos caramurus e restauradores, tendo os exaltados como uma referência distante. Ali, o liberalismo exaltado limitar-se-ia a algumas manifestações isoladas e à orientação política de Teófilo Ottoni, na Vila do Príncipe, onde encontraríamos um periódico, a Sentinela do Serro, e uma Sociedade Promotora do Bem Público, portanto, uma certa organicidade política. Tratava-se Ottoni de um liberal exaltado?

Mas, afinal, o que era um exaltado? Paulo Pereira de Castro divide a facção política exaltada em dois grupos. Um deles seria o dos "liberais puros", jeffersonianos, 
como o mineiro Teófilo Ottoni e Borges da Fonseca; o outro seria composto de "agitadores", como Cipriano Barata e Ezequiel Dias Correia, que tocavam nos perigosos ressentimentos "de classe e de raça e acena[vam] com promessas de uma nova ordem social" (Castro in Holanda, 1985, p. 9-67, 10). Nesse caso, Ottoni seria um exaltado mineiro, da estirpe dos "liberais puros".

Não entendemos como profícua, no entanto, a caracterização de Teófilo Ottoni como um liberal exaltado tout court. Na verdade, compreendemos a "democracia da gravata lavada" de Ottoni como uma dimensão do liberalismo moderado, um moderado de esquerda, diríamos hoje (Ottoni, 1930, p.20). A rigor, o "exaltamento" de Ottoni foi construído a partir de três pontos: um original republicanismo, uma proposta de reforma da Constituição sem o Senado e uma prática organizativa "popular".

Para muitos autores, sobretudo para a ferina peroração absolutista, o republicanismo não esteve ausente no alvorecer da moderação, como já o demonstramos nos episódios do governo provisional às vésperas da Independência (Silva, 2005, p.5394). Não cremos que o projeto moderado não tivesse veleidades republicanas, com uma paulatina afirmação do Parlamento e o esvaziamento do poder real, presentes, respectivamente, nas reformas e na tentativa de esvaziar o simbólico monárquico (Silva, 2000). O republicanismo ottoniano, por sua vez, conciliou precocemente com a Monarquia constitucional, optando por uma "republicanização gradual", e afirmando que, naquelas circunstâncias, B. Franklin e Thomas Jefferson fariam o mesmo (Ottoni, 1930, p.23).

Cremos, portanto, que o projeto republicano de Ottoni, pelo seu gradualismo e indefinição, identificava-se com a essência do projeto moderado, diferindo apenas em ritmos e andamentos conjunturais. Era na lógica moderada, afinal, que Ottoni explicava a conciliação com a Monarquia:

Órgão e defensor da democracia pacífica, o redator da Sentinela do Serro em tal contingência preferiu acostar-se ao princípio monárquico, contanto que a monarquia fizesse por meio de reformas legais na Constituição largas concessões ao princípio democrático. (ibidem, p.20)

Em parte, o republicanismo de Ottoni, a sua "democracia da classe média, ... de gravata lavada", trazia a esterilidade da utopia. No Brasil escravista de princípios do século XIX, Ottoni buscava uma classe média, um contingente de proprietários empreendedores, entusiastas do trabalho livre e da auto-sustentação econômica, quadro inexistente mesmo na peculiar Minas Gerais. Desejava "o governo da burguesia, e não 
propriamente do povo, das massas" (Souza, 1988, p.206). Indicava a insuficiente educação política, de "trezentos anos de escravidão", no sentido de despotismo, como uma defasagem em relação aos americanos do Norte (ibidem, p.22).

É importante observar que Teófilo Ottoni não promoveu uma pedagogia política própria, que combatesse a escravidão e o latifúndio; sua utopia contava com a existência de uma sociedade que, naturalmente, superasse esses vícios. Regina Horta Duarte aponta essas contradições na "obsessão pela coerência" de Otoni, em seu silêncio acerca das desigualdades sociais e adesão aos moderados, pelo receio da "anarquia" (Duarte, 2002, p.101-10).

Essa dimensão utópica desdobrar-se-ia no projeto do Vale do Mucuri, e sobretudo em sua Filadélfia, uma sociedade de proprietários empreendedores educados na prática da cidadania, sem escravos ou latifúndios (Duarte, 1998, p.109-20, 1998), um modelo que mostraria à sociedade imperial um novo caminho. Como esperança dessas profundas transformações restaria a imigração, meio que sugeria a europeização e uma solução asséptica em relação à população nativa ${ }^{4}$. Numa paráfrase histórica, Ottoni seria um “capitalista utópico", a República ottoniana era prisioneira dessa utopia.

A proposta de reformas da Sentinela do Serro, expostas em 25 de junho de 1831, não ultrapassou os limites que nortearam o projeto aprovado pela Câmara de maioria moderada, em 13 de outubro do mesmo ano, com as Assembléias Provinciais, o cerceamento do poder moderador e a abolição da vitaliciedade do Senado (Ottoni, 1930, p.24). O plano conjuntural de Ottoni de, talvez, apressar a sua "republicanização", foi a tentativa de golpe parlamentar em princípios de 1832. Buscou o liberal mineiro a mobilização da sociedade local e intentou empolgar a Província, secundado ainda por outro periódico do Norte de Minas, o Diamantino, do arraial do Tijuco, utilizando-se dos meios já consagrados pela ação moderada mineira: a imprensa, com a Sentinela do Serro, a sociedade política, com a Promotora do Bem Público, e as representações às Câmaras e às outras folhas e sociedades.

À vista disto julga a Sociedade Promotora do Bem Público, que os Brasileiros devem prevenir o caso, de que o Senado não anua ao projeto de reformas aprovado na Câmara dos Deputados; parecendo-lhe mais, que neste caso seria contradição admitir os votos dos atuais Senadores para as reformas, que se houverem de fazer; e firmada nestas razões deliberou convidar a todas as municipalidades, e Sociedades patrióticas não só desta como das outras Províncias, para que no caso de que até o dia da convocação da futura Assembléia Legislativa não tenha ainda passado, ou tenha sido rejeitado no 
Senado o projeto das reformas Constitucionais se esforcem em comum acordo para que nos respectivos círculos eleitorais se dêem poderes constituintes aos futuros Deputados para reformarem a Constituição ..., fazendo a reforma independente do Senado;... 5

Em que consistia a novidade serrana? Essa ação política se dava com base nas propostas acolhidas, também, pelos liberais moderados (o projeto da Câmara dos Deputados), pelos meios de pedagogia política desenvolvidos pelos moderados mineiros e realizava a exclusão do Senado, órgão criticado pela moderação e contemplado com a perda da vitaliciedade no projeto de reformas. Além disso, se vitorioso, o golpe de Ottoni instituiria como centro de poder o Parlamento de orientação moderada.

Ainda assim, a proposta da Sociedade Promotora do Bem Público da Vila do Príncipe seria duramente rejeitada. A sua congênere de Ouro Preto, a moderada Sociedade Promotora da Instrução Pública, repudiava o plano, e o poder provincial, nas figuras do promotor do júri, do Conselho Geral da Província e de seu presidente, buscava criminalizar o artigo da Sentinela. Surgiam "boatos aterradores" de descontentamento de cidadãos e de "pessoas mal-intencionadas" na Vila do Príncipe 6 . Buscava-se isolar a iniciativa conjunta da Promotora do Bem Público e da Sentinela, de "grande imprudência (e até criminosa)", como uma ação de mal-intencionados e "crédulos", não representativos, pois, da opinião geral. Assim, oficiava o presidente da Província, liberal-moderado, Manoel Ignácio de Mello e Souza, em 7 de abril de 1832: “... a tranqüilidade publica não fora nem levemente alterada; e que os habitantes do Município estão na firme convicção de evitar os extremos sempre perigosos, e manter o Governo Legal, e esperar as reformas pelos meios marcados na Constituição” (ibidem).

Também o Diamantino seria fortemente atacado, de forma paternal, por "proposições que nada têm de prudentes", frutos do "fogo patriótico da juventude". Não obstante o cuidado moderado, a proposição seria duramente antagonizada, como "perigosa e impolítica"7. O principal periódico moderado defendia a "federação", elogiava o exemplo dos Estados Unidos, provavelmente citado pelo Diamantino ${ }^{8}$, mas estigmatizava a suposta forma violenta sugerida e afirmava a legalidade:

Somos o primeiro a desejar as reformas da Constituição: somos panegirista da federação; quiséramos vê-la hoje mesmo estabelecida entre nós; sentimos as vantagens que necessariamente hão-se de resultar à Nossa Pátria de um sistema que nos aproximará tanto d'esse que com sobeja razão admiramos em os Estados Unidos: mas dar-nos há tudo isto o direito de dizer ao povo: se as reformas não forem feitas já, pegai em armas, e ide bater meia dúzia de velhos que tem assento na Câmara vitalícia, e obrigai-os a que por força decretem o que 
eles talvez julguem não convir aos vossos interesses, munidos de poderes que em boa fé receberam de vós mesmos?

$\mathrm{O}$ enquadramento da iniciativa dos liberais da vila do Príncipe dirigia-se às vicissitudes de mobilização popular presentes nas representações da Sentinela e Sociedade do Bem Público. Não era de somenos importância a divulgação do isolamento da iniciativa "criminosa", reforçando a moderação da opinião geral da Província e a inconsequiência dos extremos. A questão das reformas, ainda que reconhecida como anseio popular, era condicionada à preservação da unidade nacional e ao combate à revolução.

A necessidade que há de aceder ao voto popular, que exige a Reforma Constitucional, senão tão ampla como sairá do seio da Câmara temporária, ao menos tal que satisfaça as reclamações contra a demasiada centralização; é evidente, e os ditames da prudência, aos quais não é estranho o princípio que de dois males cumpre escolher o menor, parecem ordenar mais que tudo que não se arrisque na crise atual o Império a uma revolução violenta, que facilmente poderia ter lugar no caso de se frustrarem as esperanças dos reformistas. Os ambiciosos e agitadores não deixariam de aproveitar pretexto tão plausível para porem o estado em desordem, e talvez para dissolverem o Corpo da Nação. ${ }^{10}$

Não é surpresa, portanto, que o golpe parlamentar intentado com a "Constituição de Pouso Alegre", ainda em julho de 1832, tenha praticamente repetido a fórmula da Vila do Príncipe, representando para Ottoni a justificativa de suas ações ${ }^{11}$. O que diferia o golpe dos deputados moderados era a sua decisão centralizada, "pelo alto", ainda que não tivesse dispensado o concurso das Guardas Nacionais e de "populares" na Corte. Entre Ottoni e os moderados mineiros, quanto às reformas, restavam diferenças de tempo e graus, de difícil avaliação, de participação popular. O alinhamento político era, na prática, moderado, em torno de seu projeto e de suas lideranças: “... era somente em comunhão, com o Snr. Diogo Antônio Feijó e com as notabilidades parlamentares do último quadriênio que eu admitia a possibilidade de obter-se uma reforma mais liberal em a nossa Constituição" (ibidem, p.20).

A realidade das contradições do Império era, no entanto, muito diversa das condições ideais buscadas por Ottoni. O liberalismo exaltado, como o fundado no Rio de Janeiro, buscava apoio em massas pouco educadas, marcadas pela origem mestiça e escrava e, principalmente, enfrentava o poder com ações violentas e desordenadas. Para o jefersoniano da Vila do Príncipe, os exaltados chamaram a si "elementos anárquicos", 
o que era inaceitável. Os exaltados do Rio de Janeiro, por sua vez, contavam com aquelas massas populares e, em torno delas, projetavam mudanças radicais no seio da sociedade imperial (Basile, 2000, p.148). O utopismo de Ottoni o afastava dessas classes reais e, assim, inibia mudanças que implicassem um enfrentamento pouco asséptico para seus padrões idealizados da democracia norte-americana.

Ao passo que censurava os chefes do partido liberal moderado, porque desvirtuavam a revolução, de que se haviam apoderado, a Sentinella do Serro com mais energia estigmatizava os excessos anárquicos aplaudidos pelas folhas democráticas da Corte. (Ottoni, 1930, p.20)

Assim, alinhado com os liberais, combateu a reação monárquica, e, no seio liberal criticou a moderação hesitante e o recrutamento de "elementos anarquistas" pelos exaltados. Ottoni estabelecia uma espécie de moderação no âmbito liberalmoderado. Restaria apenas um lamento em memória da inexistente "democracia pacífica..., da classe média”.

E se a democracia criasse então uma oposição regular, eu me não provavelmente para os moderados. Porém, a oposição começou a revolver na corte e na Bahia os mais perigosos instintos da nossa sociedade, chamou em seu apoio a espada de militares indisciplinados, quando se tratava de da solução das mais graves questões constitucionais. (ibidem)

O radicalismo de Ottoni soçobrava, pois, à sua idealidade e à poderosa lógica moderada: "nos arriscamos a perder o muito que temos pelo pouco que nos resta ganhar, e que o tempo pode trazer serenamente". Assim, diante da "perseguição política" moderada, e o conseqüente fechamento da Sociedade Promotora do Bem Público e da Sentinela do Serro, os liberais do Serro "não tiveram outro recurso senão o [de] deixar o campo aos seus adversários ... e retirar-se completamente da cena" (ibidem, p.22 e 28). O alinhamento moderado, de ação intermitente, reanimar-se-ia com a Sedição restauradora de 1833 e manter-se-ia até o Movimento de 1842, no qual Teófilo Ottoni lutaria ombro a ombro com os moderados e proprietários mineiros. O Ato Adicional de 1834 seria compreendido por Ottoni como a realização de seu programa, em "um penhor de aliança que aos líderes mais adiantados ofereciam os estadistas moderados, senhores da situação" (ibidem, p.32-3 e 40).

Outras manifestações exaltadas em Minas só podem ser consideradas como fatos isolados, carecendo de maior expressão, aliás, nos dois sentidos do termo, como de 
pouca importância e de pouca clareza de motivações e objetivos. Outras seriam apenas pequenas divergências no seio moderado. Em setembro de 1831, O Universal publicava uma missiva do alcunhado de $O$ Desesperado. Seu autor fazia uma análise da evolução das posições do periódico quanto à questão das reformas, sustentando um recuo deste. Afirmava $O$ Desesperado ser moderado, mas ressalvava: "moderação tem limites". Ainda que crítico da posição do Universal, que foi claudicante quanto às reformas, $O$ Desesperado mostrava-se leitor assíduo e, portanto, participante da sociabilidade moderada. Suas críticas eram de grau, uma vez que questionava a vitaliciedade do Senado e as franquias provinciais, não ausentes do ideário e da pedagogia moderada. A publicação da missiva demonstrava o interesse do principal órgão moderado em incorporar essas críticas à sua orientação.

Acertavam, pois, em sua avaliação, os moderados de Minas, quando afirmavam sua inexistência ou inexpressão na Província: "Felizmente eles ou não existem na nossa Província, ou se alguns há, a maioria os suplanta de tal sorte que nem ousam aparecer" $^{\prime 12}$. A tarefa moderada, porém, não era a da constatação, mas, sim, a da construção dessa realidade e dessa percepção. Os exaltados não existiriam se a Província não os conhecesse e neles acreditasse, a Província não os conheceria e neles acreditaria se eles não existissem, como asseveravam os moderados.

No plano nacional, o liberalismo exaltado representou, com razoável amplitude, uma oposição ao projeto político moderado. Com o 7 de Abril a unidade liberal construída contra D. Pedro I cindiu-se, e uma miríade de idéias e comportamentos emergiu no plano político da época. Os motins da Corte do Rio de Janeiro seriam um divisor de águas do liberalismo. A interpretação dos acontecimentos segmentou a opinião liberal, as propostas que pipocavam nos periódicos expunham uma inquietante diversidade de caminhos do liberalismo.

De um lado A Aurora Fluminense condenava duramente a anarquia, de outro surgia um conjunto de periódicos exaltados, Nova Luz, Jurujuba, Exaltado, Sentinela da Ilha das Cobras e Voz da Liberdade, que, levados "pelo fogo das paixões políticas", defendiam as agitações (Azevedo, 1871, p.276-92, p.290-1). A leitura liberal moderada classificava os motins como atos criminosos, negando-lhes quaisquer propósitos políticos mais nobres.

Numa outra dimensão exaltada, encontramos o federalismo das províncias do Norte, em que se destacava o Repúblico, de Borges da Fonseca. Nesse sentido, 
imprimia-se um teor regional que se confundia com uma rivalidade entre as províncias do Sul e do Norte. Em meados de 1831, dava-se uma polêmica divulgada pelo Universal sobre a declaração do redator do Repúblico de que as províncias do Norte sustentavam a nação, ao contrário de Minas e São Paulo ${ }^{13}$.

O liberalismo exaltado penetrava na Província de Minas, por meio de emissários e periódicos ${ }^{14}$, tornando-se uma preocupação dos moderados vigiar estes emissários e, em especial, combater as idéias que timidamente alcançavam alguns mineiros.

Da Corte tem vindo, segundo é fama, alguns emissários pregar entre nós a doutrina dos revoltosos: eles chegam munidos de números da Nova Luz, e com este breve da marca trabalham por desorientar o nosso povo; felizmente eles nada têm conseguido, porque aos seus intentos se opõem o caráter e índole dos Mineiros; mas nem por isso devem os senhores Juízes de Paz deixar de empregar toda a vigilância contra tais emissários, fazendo-lhes aplicar as penas das Leis, que infringirem. ${ }^{15}$

Os moderados mineiros buscavam apresentar o pensamento exaltado como confuso, "farroupilha a linguagem, farroupilha o discurso" ${ }^{16}$ e ambicioso, na intenção de enganar "incautos e ignorantes", disposto a revoluções sangrentas com o fito de empolgar vantagens. Negavam uma pretendida preeminência exaltada no 7 de Abril e estabeleciam uma oposição entre razão e sociedade e paixões e intrigas. Os exaltados eram criminalizados pela pedagogia moderada: “... rusguentos ... à frente de uma multidão desordenada, que só queria o roubo, o assassinato, a violência, e todo gênero de crimes contra a Sociedade ..."17

Tendo o seu móvel político assentado em interesses e paixões, os "canibais" subverteriam os termos da construção liberal, uma vez que as instituições eram atacadas na torrente dessa irracional violência. Na lógica moderada, importava, sobretudo, preservar o Parlamento e a Regência.

... maldizem do Governo; menoscabam a Assembléia; concitam as Províncias onde não são ainda bem conhecidos; fazem correr aí o sangue; aumentando os descontentes com deportações tão injustas como ilegais; procuram sob o pretexto de reforma na Constituição a sua ruína, querendo que ela se faça violentamente, e for dos limites que a mesma Constituição prescreveu; e por fim baralhando tudo, transtornam a ordem, e fazem derramar o sangue inocente. ${ }^{18}$

$\mathrm{Na}$ difusão do pensamento exaltado pelas províncias era denunciada a tendência separatista e fragmentadora, nos moldes das repúblicas do Sul da América, por meio da 
violência. Os acontecimentos do centro levavam para as províncias o "fermento da desordem" 19 .

Eu tremo quando me recordo dessas 36 horas de Pernambuco, desses massacres, roubos, e todo gênero de insultos à honra, e à virtude em tão curto prazo; dessas cenas de luto, de susto, e de sangue que se reproduziram nas Províncias do Norte, e nos Sertões da Província da Bahia, na de Goiás \&c. ... Eis os frutos das instigações dos rusguentos, de suas emissões, e pérfidos escritos. ${ }^{20}$

Não faltaria a acusação de republicanos, em que, na perspectiva evolucionista moderada, seria exposta a argumentação central contra o liberalismo exaltado: a pretensão de mobilizar massas ignorantes e mestiças, sem virtudes, numa aventura republicana precipitada.

Não se lembram, nem conheceram ao menos que o presente estado da nossa civilização, a massa heterogênea da nossa população, o vasto litoral que ela ocupa não são elementos próprios para manter esse Governo, aliás excelente, quando a virtude tem o seu poderio sobre todos os seus cidadãos, ... ${ }^{21}$

Diante da "massa heterogênea", os moderados mineiros exigiam dos exaltados a prática de uma pedagogia política de cunho moderado, preservadora da ordem social. $O$ Universal de Ouro Preto, principal periódico moderado mineiro, admoestaria a Nova Luz Brasileira: “... nem por isso concitemos o povo a uma nova revolta. Acostumá-lo a desobedecer a miúdo às Autoridades, é prepara-lo para a Anarquia, habilita-lo para quebrar os vínculos sociais." 22

De forma sutil, já que não se falava em escravatura, incluía-se nessa massa heterogênea, ou no contato com ela, o perigo das rebeliões escravas: "tentarão reduzir o Brasil a um novo Hayti?". Massas heterogêneas, escravos e multidões urbanas, são apontadas como o material perigoso manipulado pelos exaltados. Apesar das características peculiares da economia de abastecimento mineira ${ }^{23}$ - maior integração social à produção e ao comércio, variadas relações com a propriedade, "democratização" da escravidão, proto-indústria e diversidade de ofícios - , esses marginalizados não deixavam de existir na Província. Ainda em fins de 1830; o correspondente à Estrela Marianense, periódico moderado de Mariana, cognominado $O$ Amante da Justiça, afirmava:

... a plebecula [sic] porém é que ordinariamente faz motins. Em todos os cantos da nossa Cidade se encontram de dia, e de noite, grupos de tais indivíduos, e de 
escravos a jogar, a proferir obscenidades, e a praticar outros atos que muito perturbam a moral pública. ${ }^{24}$

E o que movia os exaltados a arriscarem-se nas "águas turvas"? Os cargos e as vantagens. A ação política exaltada era resumida na integração entre elementos irracionais, o ódio e a violência, e, sobretudo, mesquinhos, pois, "só amam o seu bem particular" e "só aspiram à dissolução social" 25.

Apontava-se o caráter pessoal e fortuito das ações exaltadas, em contraposição à coerência do projeto moderado. Comentando um motim de 12 de junho de 1831, da "Soldadesca insurrecionada", destacava-se a ocorrência de roubos e assassinatos, no correr da "carnagem". O Universal, em seu Interior, observava que

...agregando-se-lhe homens bem conhecidos pelos seus sentimentos anárquicos, começaram a pedir o que a cada um lembrava, e suas paixões exigia (sic). Um grupo gritava venha a cabeça do Deputado Fulano, a do Deputado Sicrano; outro grupo - abaixo a Regência... ${ }^{26}$

A violência e a anarquia criadas pelos "liberais de cacete e punhal", punham em risco o próprio 7 de Abril, visto que os "anarquistas pretendem por meios indiretos, e sem o pensarem mesmo, fazer bom o governo de D. Pedro, e reanimar os seus partidistas" ${ }^{, 27}$. Ou ainda abriam caminho para um novo despotismo. Em polêmica com a Nova Luz Brasileira, O Universal questionava: "Que importa que o Estado seja regido por um, ou por muitos déspotas? Isso é para a nação de todo indiferente, se não mais pernicioso o despotismo de muitos que o de um só..."28. Esta interpretação ganharia força com a aproximação entre exaltados e caramurus.

os partidos retrógrado e rusguento, continuavam também a manobrar às escondidas para o fim de deitar abaixo o Governo, o que eles pretendem conseguir dando-se as mãos; resta saber qual deles depois da vitória iludirá o mais fraco, ou o mais crédulo. ${ }^{29}$

O risco máximo, no entanto, era o de pôr em risco a ordem social, pois "outros Sansões lançam mão às colunas do edifício social para as derribar"30. Diante do "quadro do temor de uma revolução", temia-se pelo "edifício social", que, no contexto mineiro, representava a complexa economia abastecedora, com um leque de agricultores, artistas (artesãos), comerciantes e "sábios".

Quando em um estado observa-se por toda a parte o respeito às leis, quando o amor da Pátria abrasa os corações dos cidadãos, quando cada um destes põe seu maior cuidado na pratica de seus deveres cívicos, e religiosos, é quando uma 
Nação tem o sinal mais certo de sua ventura e prosperidade. O pobre agricultor alegre arroteia seu campo, e sem temor de ver suas searas incendiadas pelas abrasadoras canículas da guerra civil, espera com a próxima colheita satisfazer as precisões da sua miséria; o artista sem temor de ver inútil o fruto do seu trabalho, remédio único de sua pobreza, possui-se do desejo de aperfeiçoá-lo, e mesmo de inventar, quando é ajudado pelo engenho; o comerciante que só na paz acha interesse procura o porto, que lhe o oferece; o sábio que só na solidão pode achar asas ao vôo de seu espírito, e que tanto distrai-se com o fragor das armas corre a encontrar aí um lugar próprio para suas meditações; assim prospera a agricultura, aperfeiçoam-se as artes, anima-se o comércio, progridem as ciências; e a Nação aumentando com estes mananciais da prosperidade, e da riqueza bem depressa torna-se venturosa, e feliz. ${ }^{31}$

Buscava-se estigmatizar as lideranças e as práticas exaltadas, justificando mesmo a ação repressiva do governo regencial. Assim, $O$ Universal, de 16 de junho de 1831, noticiava a chegada ao Rio de Janeiro, preso, do "Bacharel Cipriano José Barata d'Almeida", indicando a justeza da ação repressiva: "Entre várias causas que se apontavam, parece ser a mais exata que aquele homem estava tramando a queda do atual sistema, e sublevando para isso a gente de cor." 32 . Combatia-se o "partido de exaltados" do "Doutor Barata"33 e outros próceres radicais, ironizando sua importância para a nação: “... e os únicos que podem salvar a Nação são os Jurujubas, Exaltados, Sentinela Barata, que agora prega claramente a dissolução do pacto social, e os rusguentos de cacete, e punhal, miseráveis, e vendidos agentes dos invisíveis !!!”34

Na sua caracterização dos exaltados, que se tornaria dominante na Província pela força dos seus meios de difusão, os moderados omitiriam algumas propostas mais específicas surgidas no seio do liberalismo radical. Sobretudo aquelas que extrapolavam o plano institucional e o ideário liberal, no sentido da igualdade social e da democracia.

Foram ignoradas propostas como a do voto feminino, o fechamento dos portos às mercadorias inglesas e a suspensão do pagamento dos empréstimos contraídos com a Inglaterra, o tabelamento de alugueres e víveres, o apoio financeiro governamental à indústria nacional, o direito ao voto pelas "virtudes e talentos" (e não pela renda), o aproveitamento da mão-de-obra nacional (ao invés da imigração européia), a implantação de uma proto-lei do ventre livre, uma reforma tributária contenciosa e, mesmo, uma espécie de reforma agrária na forma do "Grande Fateusim Nacional", que propunha o aforamento de terras por 30 ou 40 anos, em quantidade limitada, para os lavradores pobres, e ainda a recuperação pelo governo de propriedades ilegais, com o mapeamento e o cadastro de todas as terras (Basile, 2000). 
A hegemonia moderada produziria, também a mobilização da Província em tropas de linha e voluntárias ${ }^{35}$. A iniciativa da moderação mineira chegou a estimular a formação de uma liga de combate aos anarquistas, pondo sob a proteção do governo de Minas diversas vilas da Província do Rio de Janeiro ${ }^{36}$. Na sua fala ao corpo de voluntários formado em Ouro Preto, o comandante do Batalhão exaltava a "fidelidade Mineira" para "esmagar a Hydra da discórdia" 37.

\section{REFERÊNCIAS BIBLIOGRÁFICAS:}

AZEVEDO, M. Sedição militar na Ilha das Cobras. Revista do IHGB, t.34, 1871.

BASILE, M. O. N. Anarquistas, rusguentos e demagogos: os liberais exaltados e a formação da esfera pública na corte imperial. Rio de Janeiro, 2000. Dissertação (Mestrado em História) - IFCS, UFRJ.

BERNSTEIN, S. Os partidos. In: RÉMOND, R. (Org.). Por uma História Política. Rio de Janeiro: UFRJ/ FGV, 1996.

DUVERGER, M. Os partidos políticos. Rio de Janeiro: Zahar, 1970.

GRAÇA FILHO, A. A. \& LIBBY, D. C. e A economia do Império brasileiro. São Paulo: Atual, 2005, 107 p.

GRAMSCI, A. Cadernos do cárcere, Rio de Janeiro: Civilização Brasileira, 2000, v.3. $428 \mathrm{p}$.

GUIMARÃES \& PRADO, L. M. P. e M.E. O Liberalismo no Brasil Imperial: conceitos, origens e prática. Rio de Janeiro: Revan: UERJ, 2001.

HOLANDA, S. B. (Org.). História geral da Civilização Brasileira, 5.ed. São Paulo: Difel, 1985. t.II, v.2.

LIBBY, Douglas Cole. Transformação e trabalho em uma economia escravista: Minas Gerais no século XIX. São Paulo: Brasiliense, 1988, 404 p.

MARSON, I.A. Movimento praieiro 1842-1849. São Paulo: Moderna, 1980.

MOREL, M. As Transformações dos Espaços Públicos: imprensa, atores políticos e sociabilidades na cidade imperial (1820-1840). São Paulo: Hucitec, 2005, 326p.

MOTTA, P. R. Movimentos partidários no Brasil. Rio de Janeiro: FGV, 1971, 95p.

OTTONI, T. Circular dedicada aos senhores eleitores de Minas Gerais (1860). São Paulo: Irmãos Ferraz, 1930, 168p. 
SILVA, W. Pedro, de perpétuo a panaca: elites políticas provinciais em combate ao poder simbólico monárquico. Tempos Gerais - UFSJ, São João del-Rei, n.1, 2000.

Autonomismo, contratualismo e Projeto Pedrino: Minas Gerais na

Independência. Revista de História Regional-UEPG, Ponta Grossa, v.10, n.1, p.53-94, Verão, 2005.

SOUZA, J. M. Cidade: momentos e processos - Serro e Diamantina na formação do Norte mineiro no século XIX. Belo Horizonte, 1991. Tese (Doutorado em Sociologia) FAFICH, UFMG.

SOUZA, O.T. Fatos e personagens em torno de um regime. Belo Horizonte: Itatiaia, 1988, 337p.

WERNET, A. Sociedades políticas (1831-1832). São Paulo: Cultrix/Mec, 1978, 153p.

SILVA, Wlamir. Crushing the Hydra of the Discord: the framing of the thought exalted by the mining moderation. História, São Paulo, v. 25, n. 2, p. 214-227, 2006.

Abstract: In the construction of the mining moderate identity, basic for its hegemony composition, its delimitation by the elements that were potentially dangerous to it or that were opposed to it was inestimable. Among them we point out the exalted liberalism, which was essentially an absence. This, however, counted on the liberal-moderate pedagogy contribution, which has classified it as violent and irrational, passionate, revengeful and ambitious, in opposition to the moderate reason, and vehicle of a bloody revolution, involving color people, incautious ones and ignorants. Thus, interpreting and influencing the productive mining society, the moderate-liberal ones could isolate the "exalted virus", imposing its logic and exercising its hegemony.

Keywords: Political culture; political identities; political hegemony.

Artigo recebido em 9/2006. Aprovado em 12/2006.

\section{NOTAS}

\footnotetext{
* Doutor em História Social pela Universidade Federal do Rio de Janeiro (UFRJ) e Professor do Departamento de Ciências Sociais da Universidade Federal de São João del-Rei (UFSJ), CEP: 36307 352, São João del-Rei-MG, e-mail: wmsilva@mgconecta.com.br.

${ }^{1}$ Para uma classificação mais nuançada, a partir do olhar estrangeiro, ver Morel, 2005, capítulo 2.

2 Os grupos políticos regenciais não se enquadram numa conceituação rígida de partido, cremos, no entanto, ser de maior eficácia historiográfica a conceituação mais ampla proposta por Gramsci, 2000, v.3, p.253. Cremos que os grupos moderado, exaltado e restaurador foram os primeiros partidos políticos brasileiros, considerados na sua articulação no Parlamento, na imprensa e nas sociedades políticas. Ver
} 
Motta, 1971, p.1-2, e Wernet, 1978. Para uma abordagem mais restritiva do conceito de partido, ver Duverger, 1970; Bernstein, 1996, p.57-98, e Guimarães in Guimarães \& Prado, 2001, p.73-101, p.103.

${ }^{3}$ De fato, também no Rio Grande do Sul opuseram-se caramurus e liberais. Em Pernambuco predominou uma certa indefinição sob o rótulo de liberais (ver Marson, 1980, p.117).

${ }^{4}$ Apud Souza, 1991, p.95. Mesmo os exaltados da Corte também não propunham a abolição imediata da escravidão, limitando-se a propostas mais avançadas de abolição gradual, mas não incentivavam a imigração estrangeira, alegando que seria "constituir os Brasileiros na categoria de escravos a estrangeiros" (cf. Basile, 2000, p.119-20 e 132-33).

${ }^{5}$ Representação da Sociedade Promotora do Bem Público, estabelecida na Vila do Príncipe, em 2 de fevereiro de 1832, apud Astro de Minas, São João del Rei, no 669 18/03/1832. Um artigo da Sentinela do Serro com o documento da Sociedade Promotora é reproduzido em Ottoni, 1930, p.25-7.

${ }^{6}$ O Universal, Ouro Preto, n.762 - 5/06/1832.

${ }^{7}$ O Universal, Ouro Preto, n.723 - 14/03/1832. Ver também, n.644 - 09/09/1831.

${ }^{8}$ Não conhecemos acervo do Diamantino.

${ }^{9}$ O Universal, Ouro Preto, n.723 - 14/03/1832.

${ }^{10}$ Ibidem, n.771 - 06/07/1832, no mesmo sentido, ver o Astro de Minas, São João del Rei, n.726 21/07/1832, e Opinião Campanhense, Campanha, n. 8 - 22/06/1832.

${ }^{11}$ Ibidem, p.30-1. Teófilo Otoni interpreta o "golpe de estado parlamentar" dos deputados moderados como a transigência com o liberalismo avançado.

${ }^{12}$ O Universal, Ouro Preto, n.608, p.30-1. Teófilo Otoni interpreta o "golpe de estado parlamentar" dos deputados moderados como a transigência com o liberalismo avançado.

${ }^{13}$ O Universal, Ouro Preto, n.608 - 17/06/1831.

${ }^{14}$ O Universal, Ouro Preto, n.664 - 26/10/1831.

${ }^{15}$ O Universal, Ouro Preto, n.652 - 28/09/1831, no mesmo sentido, ver o Astro de Minas, São João del Rei, n.610 - 22/10/1831: "Nós lembramos aos Srs. Juízes de Paz tenham a maior vigilância sobre os indivíduos, que chegarem de novo aos seus curatos, exigindo os seus passaportes, procurando informar-se dos empregos que abraçam, e encarregando a pessoas honradas uma miúda pesquisa dos fins a que se dirigem esses novos vindos."

${ }^{16}$ Num comentário sobre o periódico exaltado Jurujuba dos Farroupilhas, de João Baptista de Queiroz. O Universal, Ouro Preto, n.657 - 10/10/1831. As duras críticas ao periodismo exaltado não impediriam de lamentar a condenação de Queiroz por crime de imprensa. Ver n.641 - 02/09/1831.

${ }^{17}$ O Universal, Ouro Preto, n.704 - 30/01/1832.

${ }^{18}$ Ibidem.

${ }^{19}$ O Universal, Ouro Preto, n.663 - 24/10/1831.

${ }^{20}$ O Universal, Ouro Preto, n.704 - 30/01/1832.

${ }^{21}$ Ibidem.

${ }^{22}$ O Universal, Ouro Preto, n.617 - 08/07/1831.

23 Desde os anos 1980 é produzida vem sendo produzida uma importante historiografia acerca da economia de abastecimento mineira, para nossos fins, apontamos Libby, 1988. Ou ainda a síntese presente em Graça \& Libby., p.16-25.

${ }^{24}$ Estrella Mariannense, Mariana, n.27 - 06/11/1830.

${ }^{25}$ O Universal, Ouro Preto, n.704 - 30/01/1832.

${ }^{26}$ O Universal, Ouro Preto, n.627 - 01/08/1831.

${ }^{27}$ O Universal, Ouro Preto, n.647 - 16/09/1831.

${ }^{28}$ O Universal, Ouro Preto, n.617 - 08/07/1831.

${ }^{29}$ O Universal, Ouro Preto, n.771 - 06/07/1832.

${ }^{30}$ O Universal, Ouro Preto, n.647 - 16/09/1831.

${ }^{31}$ O Universal, Ouro Preto, n. $808-01 / 10 / 1832$.

${ }^{32}$ O Universal, Ouro Preto, n.607 - 15/06/1831.

${ }^{33}$ O Universal, Ouro Preto, n.612 - 27/06/1831.

${ }^{34}$ Astro de Minas, São João del Rei, n.610 - 22/10/1831.

${ }^{35}$ O Universal, Ouro Preto, n.614 - 02/09/1831 e n.633 - 15/08/1831.

${ }^{36}$ O Universal, Ouro Preto, n.639 - 08/08/1831.

${ }^{37}$ O Universal, Ouro Preto, n. $627-01 / 08 / 1831$. 